\title{
Assessment of microRNA expression in leukemic cells as predictors of sensitivity to purine nucleoside analogs, fludarabine and cladribine, in chronic lymphocytic leukemia patients
}

This article was published in the following Dove Press journal:

Cancer Management and Research

\author{
Agnieszka Szymczyk ${ }^{1,2}$ \\ Sylwia Chocholska' \\ Arkadiusz Macheta' \\ Dariusz Szczepanek ${ }^{3}$ \\ Marek Hus \\ Monika Podhorecka' \\ 'Department of Haematooncology and \\ Bone Marrow Transplantation, Medical \\ University of Lublin, Lublin, Poland; \\ ${ }^{2}$ Department of Clinical Transplantology, \\ Medical University of Lublin, Lublin, \\ Poland; ${ }^{3}$ Department of Neurosurgery \\ and Pediatric Neurosurgery, Medical \\ University of Lublin, Lublin, Poland
}

Background: Great progress has been achieved lately in the therapy for chronic lymphocytic leukemia (CLL), one of the most frequently diagnosed adult leukemias. New classes of drugs, such as kinase inhibitors and BCL-2 protein antagonists, have been approved for treatment of CLL patients. Despite the abovementioned therapies the disease can still be effectively treated with purine nucleoside analogs (PNA). However, some patients, for example, those with TP53 gene abnormalities, become resistant, and the other factors involved in the therapy resistance are still being investigated. This study was aimed at analyzing the possible role of microRNAs as markers predicting the outcome of chemotherapy based on PNA - fludarabine and cladribine in CLL patients.

Methods: The expression of miR-21, miR-34a, miR-181a and miR-221 in previously separated leukemic cells was assessed with the use of qRQ-PCR technique at the moment of diagnosis in 40 CLL patients. In turn, apoptosis induced by fludarabine and cladribine in 24-hour cell culture was evaluated by determining the increase in the percentage of apoptotic cells of $\mathrm{CD} 5+/ \mathrm{CD} 19+/ \mathrm{Cas} 3+$ phenotype, using a flow cytometry method. Nine of the 40 studied subjects were treated with fludarabine-based regimens and were analyzed with regards to in vivo response to PNA.

Results: We detected a significantly higher PNA-induced apoptosis rate in patients with high miR-34a expression in comparison to low expression ones. Interestingly, such differences were detected particularly in standard cytogenetic patients.

Conclusions: These results may prove an important role of miR-34a expression as a predictor of apoptosis, even in cases when other risk factors like cytogenetic abnormalities are absent. An assessment of microRNAs expression seems to be useful as an indicator of sensitivity to PNA and may help to predict PNA-based therapy outcome.

Keywords: chronic lymphocytic leukemia, microRNA, purine nucleoside analog, prognostic markers, apoptosis

\section{Background}

Great progress has been achieved lately in the therapy for chronic lymphocytic leukemia (CLL), one of the most frequently diagnosed adult leukemias. ${ }^{1,2}$ New classes of drugs, such as oral kinase inhibitors (ibrutinib, idelalisib) and BCL-2 protein antagonists, which induce apoptosis in leukemic cells, have been approved for treatment of CLL patients. ${ }^{3,4}$ However, the disease can still be effectively treated with purine analogs, alkylating agents, bendamustine, glucocorticoids, or monoclonal antibodies. Clinical course and prognosis
Correspondence: Agnieszka Szymczyk Department of Clinical Transplantology Medical University of Lublin, Staszica II Str., 20-08I Lublin, Poland

Tel +48 8I 5345496

Email agnieszka.szymczyk.med@wp.pl 
of this type of leukemia are highly variable. Some patients with benign disease never require therapy and die because of causes other than leukemia. In others, the treatment is started soon after diagnosis and relapses may occur early, because of the aggressiveness of the disease that is the cause of death in this group. ${ }^{5,6}$ The improved tools are used for predicting the outcome of leukemia. Some markers also allow a choice of the specific therapies with known effectiveness in the presence of certain genetic or clinical features of CLL. The most important in clinical practice are immunoglobulin heavy chain genes (IgVH)), ZAP-70 and CD38 expression being considered as indicators for $\mathrm{IgVH}$ mutations as well as gene and genomic abnormalities. ${ }^{5-7}$ Of these markers clinical features like age or the presence of comorbidities have also shown independent prognostic value in multiple prospective trials, but finding the new prognostic and predictive factors which will help to improve therapy results is still of importance.

Research on CLL pathogenesis revealed lots of mechanisms involved in leukemic transformation. The B cell receptor signaling induces survival of leukemic lymphocytes. Proproliferative signals are also mediated from the microenvironment. ${ }^{7-9}$ Additionally, several genetic alterations like the single-nucleotide polymorphisms, chromosomal alterations and alterations in microRNAs (miR) were reported. ${ }^{8,10}$ MicroRNAs are epigenetic modulators of gene expression and cellular signaling pathways. They are reported to be deregulated in human cancers acting as inducers or suppressors of tumor growth. ${ }^{11-13}$ CLL was the first neoplastic disease in which deregulation of microRNAs miR-15a and miR-16-1 both targeting BCL2 and MCL1 expression and leading to apoptosis resistance are detected. ${ }^{14}$ Currently the microRNAs are widely examined as prognostic factors in proliferating diseases, particularly with regards to their ability of predicting therapy outcome.

The aim of this study was to analyze the possible role of chosen microRNAs expression as markers predicting the outcome of chemotherapy based on purine nucleoside analogues (PNA) - fludarabine and cladribine. PNA, in particular fludarabine, in combination with alkylating agents and monoclonal antibodies are still used as first line-therapy in fit patients with CLL, despite new forms of targeted treatment. However, there is a group of subjects who are resistant to PNA. TP53 gene abnormalities are indicators of such a resistance, but the other factors involved are being investigated. In the presented study the expression of miR-21, miR-34a, miR-181a and miR-221 in previously separated CD19+ leukemic cells was quantitatively analyzed with use of the qRQ-PCR technique.

\section{Methods}

\section{Patients and research material}

The study group comprised 40 unselected patients with CLL diagnosis, which was based on clinical examinations, morphological and immunological criteria according to IWCLL. All subjects were newly diagnosed and not treated previously. In all patients, the prognostic factors and clinical parameters were evaluated (Table 1). This cohort included patients, who were described in our previous study in which we analyzed the role of microRNAs as CLL prognostic markers. ${ }^{15}$

Samples of $10 \mathrm{ml}$ peripheral blood were collected in syringes with the anticoagulant edetate (Sarstedt, Germany).

\section{Cells isolation}

Peripheral blood mononuclear cells (PBMC) were separated from $5 \mathrm{ml}$ of peripheral blood by density gradient centrifugation (Biocoll, AG Biochrom, Berlin Germany). After washing and undergoing viability assessment, the cells were subjected to cell culture procedures or leukemic cells separation, respectively. The method of magnetic-activated cell sorting for leukemic cells separation was used according to the manufacturer's instructions $\left(\right.$ MACS $^{\circledR}$ Cell Separation, Bergisch Gladback, Germany). In this way the mononuclear cells were obtained, their viability was assessed and they were used for further procedures.

\section{RNA extraction}

The modified method of Chomczynski and Sacchi ${ }^{16}$ was used for total RNA isolation from CD19+cells. For the further procedures $10^{6} \mathrm{CD} 19+$ cells were used. Isolation of RNA was performed with the use of the mirVana Isolation Kit (Ambion, Thermo Fisher Scientific, Waltham, MA, USA). Then RNA quantity and purity was assessed using the NanoDrop 2,000 spectrophotometer (Thermo Fisher Scientific). The isolated RNA was stored at $-20^{\circ} \mathrm{C}$ until the moment of further procedures.

\section{MicroRNA quantification}

Assessment of microRNA expression was performed with the use of the TaqMan ${ }^{\circledR}$ Small RNA Assays Kit (Applied Biosystems, Thermo Fisher Scientific). Firstly, total cellular RNA was reverse-transcribed with specific primers (TaqMan ${ }^{\circledR}$ MicroRNA Reverse Transcription Kit) as indicated by the manufacturer's instruction on Applied Biosystems 7,500 Fast Real Time PCR Systems. The complementary DNA (cDNA) was obtained and it was used for the following 
Table I Prognostic factors and clinical parameters

\begin{tabular}{|c|c|c|}
\hline \multicolumn{2}{|l|}{ Number of patients } & \multirow{2}{*}{$\begin{array}{l}40 \\
\text { Md 65.5; } \min .38 ; \max .85\end{array}$} \\
\hline Age & Median (years) & \\
\hline \multirow[t]{2}{*}{ Sex } & Women & 22 \\
\hline & Men & 18 \\
\hline \multirow[t]{2}{*}{ Rai clinical stage } & Early (0-I) & 19 \\
\hline & Advanced (II-IV) & 21 \\
\hline \multirow[t]{2}{*}{ CD38 expression (cutoff point $30 \%$ ) } & Positive & 10 \\
\hline & Negative & 29 \\
\hline \multirow[t]{2}{*}{ ZAP-70 expression (cutoff point $20 \%$ ) } & Positive & 12 \\
\hline & Negative & 27 \\
\hline \multirow[t]{5}{*}{ Cytogenetic aberrations } & dell3q & 13 \\
\hline & Trisomy 12 & 3 \\
\hline & Normal & 15 \\
\hline & del IIq & 7 \\
\hline & dell7p & 3 \\
\hline Lymphocytosis (G/I) & Medium & Md 43.47; min. 5.76; max. 179.4 \\
\hline$\beta_{2}$-microglobulin plasma level $(\mathrm{mg} / \mathrm{l})$ & Medium & Md 3.05; min. I.24; $\max .7 .96$ \\
\hline Lactate dehydrogenase activity (U/I) & Medium & Md 40I.2I; min. OP256; max. 897 \\
\hline
\end{tabular}

Abbreviations: Md, median, min., minimum, max., maximum.

procedures. The quantitative analysis of microRNA expression was performed with the method of quantitative reverse transcriptase real-time PCR (qRT-PCR).The following Taqman miRNA Assays were used in this study: hsa-miR-21-5p, hsamiR-34a-5p, hsa-miR-181a-5p, hsa-miR-221-3p and hsa-miR -16 as endogenous control. Accumulation of a fluorescent signal was a measure of positive reaction. The cycle threshold (Ct) was established as the number of cycles required for the fluorescent signal to cross the threshold and exceed the fluorescence level of background. $\mathrm{Ct}$ points were inversely proportional to the amount of microRNA in the sample. Based on the endogenous control we normalized the expression of each microRNA. The method of comparative $\Delta \Delta \mathrm{Cq}$ was then applied for data analysis, and fold changes were next calculated using $2^{-\Delta \Delta \text { Cq. } 17}$ All PCR reactions were run in duplicate.

\section{Cell cultures}

Isolated PBMC at a concentration of $2 \times 10^{6} / \mathrm{ml}$ were resuspended in culture medium consisting of RPMI 1,640 with L-glutamine, penicillin, streptomycin, and 10\% fetal calf serum. This culture medium was complemented with fludarabine at a concentration of $1 \mu \mathrm{g} / \mathrm{ml}$ or cladribine at a concentration of $1.4 \mu \mathrm{g} / \mathrm{ml}$, respectively. We selected the concentrations of the drugs based on the literature and our preliminary experiments in CLL cultures, in which certain concentrations caused a significant induction in apoptosis with spontaneous apoptosis that did not exceed $50 \%$ of the total cell culture. Cell samples that were incubated in the absence of any drug and in the presence of a drug solvent for periods of time that were equivalent to the drug-treated cells were considered negative controls. All of the reagents were obtained from Sigma-Aldrich Chemie GmbH (Germany). The cells were cultured at $37^{\circ} \mathrm{C}$ in a $5 \% \mathrm{CO}_{2}$ atmosphere for 0 and 24 hours and then they were assessed for the frequency of apoptosis as described below.

\section{Measurement of apoptosis by detection of active caspase- 3 expression}

Cells that had been treated in culture with drugs were subjected to incubation with anti-CD19 PE-Cy7 and antiCD5 APC-conjugated monoclonal antibodies (mAbs) (Pharmingen $^{\mathrm{TM}}$, BD Biosciences, San Jose, CA, USA) for $15 \mathrm{~min}$ at room temperature. Subsequently, the fixation and permeabilization procedures were performed using the BD Cytofix/Cytoperm kit (BD Biosciences, San Jose, CA, USA) according to the manufacturer's instructions. The cells were then incubated with FITC-conjugated antiactive caspase-3 mAb (BD Biosciences). Acquisition and data analysis were done with the flow cytometry method using the eight-color flow cytometer FACSCanto II with 
FACSDiva Software (Becton Dickinson, USA). At least 10,000 cells of each collected sample were analyzed and populations of $\mathrm{CD} 5+/ \mathrm{CD} 19+$ leukemic cells were gated. Further analysis was done within this population. Apoptosis was evaluated by calculation of the increase percentage of cells with active caspase- 3 expression (difference between the study and the control sample).

\section{Fluorescence in situ hybrydization}

Fluorescence in situ hybridization (FISH) method was used to analyze cytogenetic abnormalities in leukemic cells. The locus-specific probes 17p13.1 (LSI TP53), 11q22.3 (LSI ATM), 13q14.3 (D13S319), 13q34, and the chromosome 12 centromere (Abott Diagnostics, Abott Park, IL, USA) were used. Procedures were done according to the manufacturer's instruction. Probes were denatured at $73^{\circ} \mathrm{C}$ for $5 \mathrm{~min}$ and then applied to the designated areas of the slides. After an overnight hybridization the slides were stained with DAPI. The cells were analyzed with BX51 fluorescence microscope (Olympus, San Jose, CA, USA), and CytoVision image analysis system. At least 200 nuclei were assessed for each probe, and the result was positive with a border value of $20 \%$.

\section{Clinical response to purine analogues-based treatment regimens}

In the studied group of patients the assessment of clinical response to chemotherapy with purine analogues-based regimens was performed. We used the criteria of response to treatment proposed by WG-IWCLL in 2008 based on WG-NCI criteria from $1996 .{ }^{18,19}$ According to these criteria, complete response required the absence of symptoms and organomegaly, normal complete cell counts of peripheral blood, less than $30 \%$ of lymphocytes in bone marrow for at least 2 months. When size of the lymph nodes, spleen and liver, together with the peripheral blood data, were at least $50 \%$ better than pre-treatment values, the partial response was achieved. Other patients were considered non-responders.

\section{Statistical analysis}

Statistical analysis was done with STATISTICA 12.0 software for Windows. The Shapiro-Wilk test was used to assess the variables. Futher statistical analyses were conducted on the basis of non-parametric tests (Mann-Whitney
$\mathrm{U}$ test for 2-category variables, Kruskal-Wallis test for more than 2-category variables, Spearman's rank correlation test for studying dependencies between variables) and Kaplan-Meier analysis. The results are shown as median or mean values with standard deviation. A value of $p<0.05$ was considered to be statistically significant.

\section{Results}

\section{Assessment of microRNAs expression in leukemic cells}

Our analysis revealed an expression of all analyzed microRNAs in leukemic cells, however the expression differs in certain cases. Thus the group of the studied subjects was divided into the subgroups with high and low expression of each microRNA, respectively. The cutoff point was established to be the mean expression of microRNA. In further analysis the groups of high and low microRNA expression were compared.

\section{Assessment of fludarabine-induced apoptosis in cell culture in relation to microRNAs expression}

Apoptosis rate was set up by assessment of the percentage of CD19+/CD5+ cells with active caspase 3 expression after 24 hours in in vitro culture. Percentage of apoptotic cells was higher in fludarabine-added culture in comparison to control culture, $19.79 \pm 8.74$ and $11.87 \pm 8.25$, respectively. Results of the increase in apoptotic cell numbers in relation to expression of miR-21, miR-34a, miR-181a, and miR-221 are presented in Table 2 . We observed statistically significant higher percentage of apoptotic cells in the group of patients with high expression of miR-34a in comparison to the group with low miR-34a expression (Figure 1A). The precise case analysis of low miR-34a and low apoptosis rate group revealed in four patients the absence of unfavorable cytogenetic risk factors that are known to be connected with apoptosis resistance. At the same time in these four subjects the unfavorable profiles of other analyzed microRNAs expression were detected (Table 3). Further assessment of apoptotic cells percentage in the group of standard cytogenetic risk revealed a statistically significant difference between high and low miR-34-a expression cases (Figure1B). We did not achieve statistically significant differences in percentage of CD19 +/CD5+ leukemic cells with regards to expression of other microRNAs examined in the study. 
Table 2 The increase in apoptotic cells percentage in fludarabine-added cell cultures of leukemic cells in relation to expression of miR2I, miR-34a, miR-I8Ia, and miR-22I

\begin{tabular}{|c|c|c|}
\hline \multicolumn{3}{|l|}{ miR-2I } \\
\hline $\begin{array}{l}\text { Low expression of miR-2I } \\
\text { High expression of miR-2 I }\end{array}$ & $\begin{array}{l}\text { Increase in the percentage of Caspase } 3+(\text { Cas } 3+) \text { cells }(M \pm S D) \\
7.54 \pm 5.33(n=22) \\
8.59 \pm 5.51 \quad(n=18)\end{array}$ & $\begin{array}{l}p \\
0.505\end{array}$ \\
\hline \multicolumn{3}{|l|}{ miR-34a } \\
\hline $\begin{array}{l}\text { Low expression of miR-34a } \\
\text { High expression of } \mathrm{miR}-34 a\end{array}$ & $\begin{array}{l}\text { Increase in the percentage of Cas } 3+\text { cells }(M \pm S D) \\
5 . I I \pm 4.50(n=I I) \\
8.7 I \pm 5.23(n=29)\end{array}$ & $\begin{array}{l}p \\
0.037\end{array}$ \\
\hline \multicolumn{3}{|l|}{ miR- I 8 I a } \\
\hline $\begin{array}{l}\text { Low expression of miR- I8 Ia } \\
\text { High expression of miR- } 18 \text { Ia }\end{array}$ & $\begin{array}{l}\text { Increase in the percentage of Cas } 3+\text { cells }(M \pm S D) \\
7.54 \pm 4.80(n=10) \\
8.16 \pm 5.61(n=30)\end{array}$ & $\begin{array}{l}p \\
0.791\end{array}$ \\
\hline \multicolumn{3}{|l|}{ miR-22 I } \\
\hline $\begin{array}{l}\text { Low expression of miR-22I } \\
\text { High expression of } \mathrm{miR}-221\end{array}$ & $\begin{array}{l}\text { Increase in the percentage of Cas } 3+\text { cells }(M \pm S D) \\
8.05 \pm 5.50(n=30) \\
7.89 \pm 5.24(n=10)\end{array}$ & $\begin{array}{l}p \\
0.900\end{array}$ \\
\hline
\end{tabular}

A

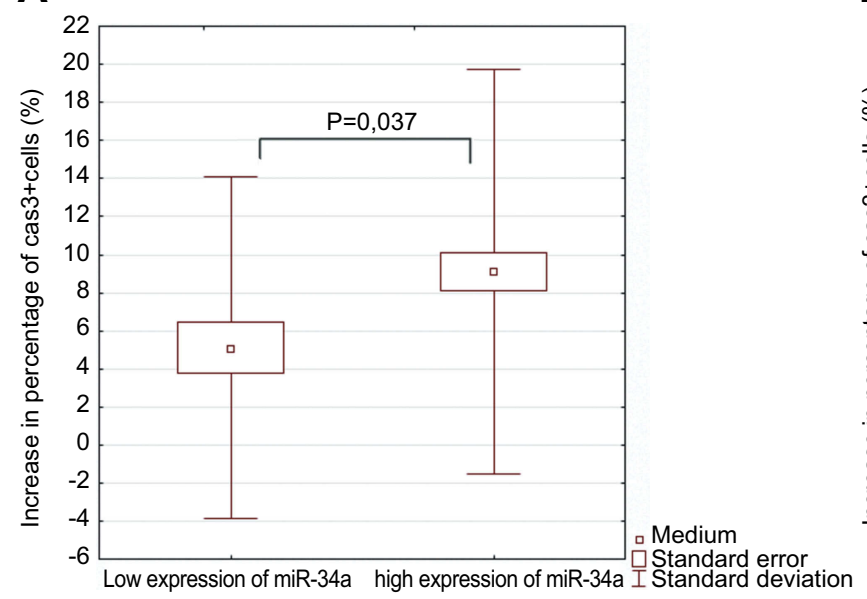

B

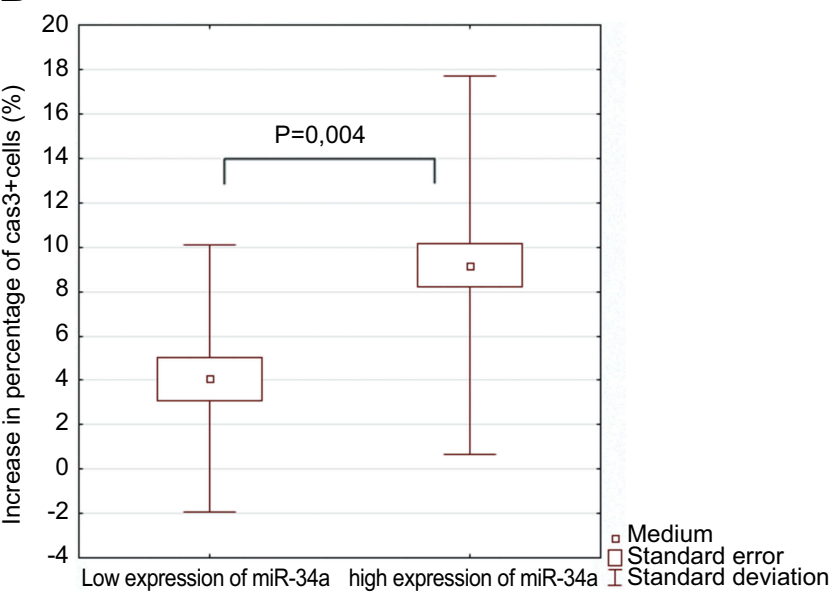

Figure I Rate of apoptosis in fludarabine-added cell cultures of leukemic cells in regards to miR-34 expression. (A) Comparison of patients with high and low expression of miR-34a, respectively. (B) Comparison of patients with high and low expression of miR-34a, respectively in standard cytogenetic risk group.

Abbreviation: Cas3+, caspase $3+$.

\section{Assessment of cladribine-induced apoptosis in cell culture in relation to microRNAs expression}

We detected a significantly higher percentage of apoptotic cells in cladribine-added cell cultures in comparison to control cultures, $18.29 \pm 8.83$ and $11.87 \pm 8.25$, respectively. The results of the increase in apoptotic cells in relations to expression of miR-21, miR-34a, miR-181a, and miR-221 in cladribine-induced cultures are presented in Table 4. We did not observe statistically significant differences in percentage of apoptotic cells in the group of patients with high expression of analyzed microRNAs in comparison to the group of low microRNAs expression. However, assessment of apoptosis in the groups of different microRNA expression with regards to cytogenetic risk groups 
Table 3 The precise case analysis of low miR-34a and low apoptosis rate group

\begin{tabular}{|l|l|l|l|l|l|}
\hline \multicolumn{2}{|l|}{ Cytogenetic abnormalities } & \\
\hline Patient no. & deletion IIq & trisomy I2 & deletion 13q & deletion 17p & Increase in the percentage of Caspase 3+ cells \\
4 & Negative & Negative & Negative & Negative & Low \\
17 & Negative & Negative & Negative & Negative & Low \\
33 & Negative & Negative & Positive & Negative & Low \\
40 & Negative & Negative & Negative & Negative & Low \\
\hline Expression of microRNAs & miR-2I & miR-34a & miR-18Ia & miR-22I & \\
\hline Patient no. & Low & Low & Low & Low \\
4 & Low & Low & Low & Low \\
17 & High & Low & Low & Low \\
33 & High & Low & Low & \\
40 &
\end{tabular}

Table 4 The increase in apoptotic cells percentage in cladribine-added cell cultures of leukemic cells in relation to expression of miR2I, miR-34a, miR-I8Ia, and miR-22I.

\begin{tabular}{|c|c|c|}
\hline \multicolumn{3}{|l|}{ Expression of miR-2 I } \\
\hline & $\begin{array}{l}\text { Increase in the percentage } \\
\text { of Caspace } 3+(\text { Cas } 3+) \text { cells }(M \pm S D)\end{array}$ & $p$ \\
\hline Low expression of miR-2 I & $6.04 I \pm 4.37 \mid$ & 0.870 \\
\hline High expression of miR-2 I & $6.800 \pm 5.738$ & \\
\hline \multicolumn{3}{|l|}{ Expression of $\mathrm{miR}-34 \mathrm{a}$} \\
\hline & $\begin{array}{l}\text { Increase in the percentage } \\
\text { of Cas } 3+\text { cells }(M \pm S D)\end{array}$ & $p$ \\
\hline Low expression of miR-34a & $7.055 \pm 5.008$ & 0.115 \\
\hline High expression of miR-34a & $4.609 \pm 4.657$ & \\
\hline \multicolumn{3}{|l|}{ Expression of miR- I8Ia } \\
\hline & $\begin{array}{l}\text { Increase in the percentage } \\
\text { of Cas } 3+\text { cells }(M \pm S D)\end{array}$ & $p$ \\
\hline Low expression of miR- I8Ia & $6.553 \pm 5.122$ & 0.743 \\
\hline High expression of miR- I8Ia & $5.870 \pm 4.744$ & \\
\hline \multicolumn{3}{|l|}{ Expression of miR-22I } \\
\hline & $\begin{array}{l}\text { Increase in the percentage } \\
\text { of Cas } 3+\text { cells }(M \pm S D)\end{array}$ & $p$ \\
\hline Low expression of miR-22I & $6.403 \pm 4.943$ & 0.888 \\
\hline High expression of miR-22I & $6.320 \pm 5.356$ & \\
\hline
\end{tabular}

revealed the differences in the case of miR-34a. In the group of standard cytogenetic risk the percentage of cladribine-induced apoptotic cells was higher in cases of high miR-34a expression in comparison to those with low expression (Figure 2A and B). The detailed case analysis revealed the absence of unfavorable cytogenetic risk factors and unfavorable profile of analyzed microRNA expression in six patients of low miR-34a and low apoptosis rate group (Table 5). We did not reveal statistically significant differences in percentage of CD19+/CD5+ leukemic cells with regards to expression of other microRNAs examined in the study. 
A

\begin{tabular}{|c|c|c|c|}
\hline \multirow{2}{*}{ Cytogenetic risk } & \multicolumn{2}{|c|}{ Expression of Cas3+(M \pm SD) } & \multirow{2}{*}{ P } \\
\cline { 2 - 3 } & Low expression of miR-34a & High expression of miR-34a & \\
\hline Standard & $3,500 \pm 3,010$ & $7,175 \pm 5,111$ & 0,056 \\
\hline High & $6,789 \pm 5,062$ & $15,700(n=1)$ & 1,000 \\
\hline
\end{tabular}

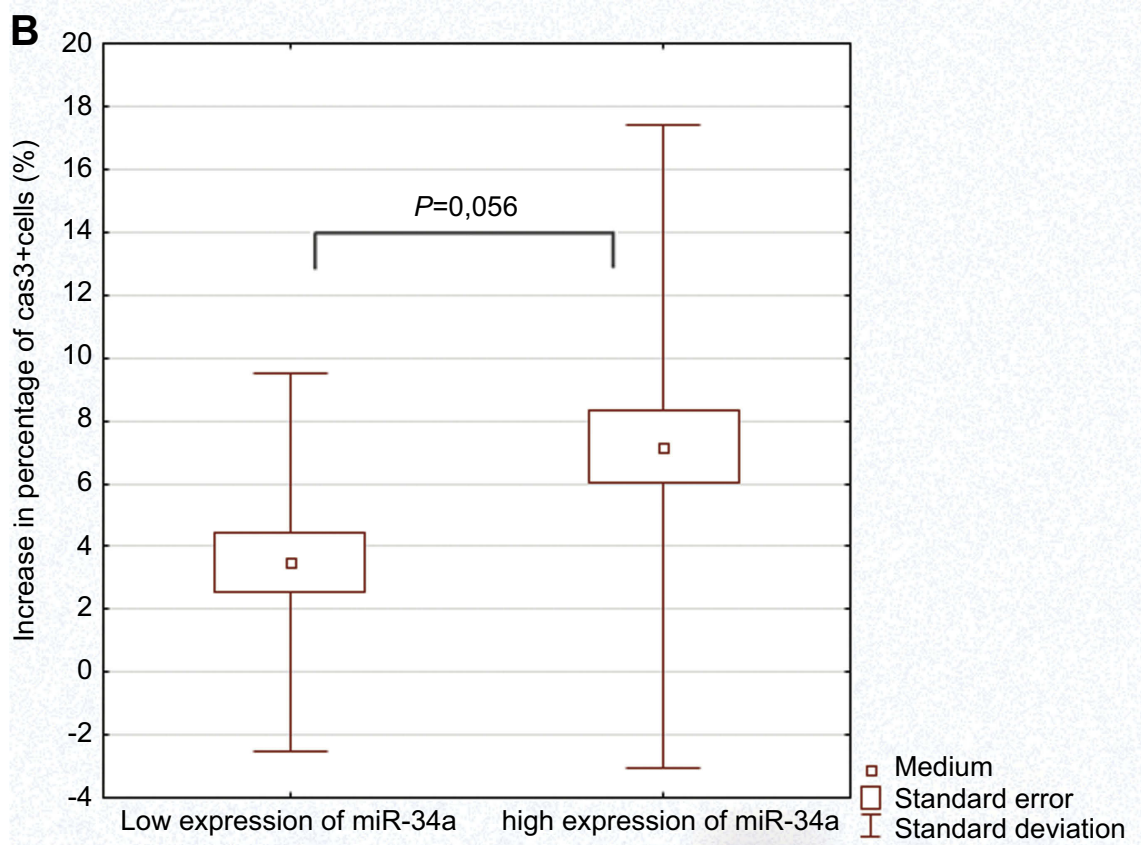

Figure 2 Rate of apoptosis in cladribine-added cell cultures of leukemic cells in regards to miR-34a expression. (A) Comparison of patients with high and low expression of miR-34a in standard and high cytogenetic risk groups, respectively. (B) Comparison of patients with high and low expression of miR-34a, respectively in standard cytogenetic risk group.

Abbreviation: Cas3, caspase 3 .

Table 5 The precise case analysis of low miR-34a and low apoptosis rate group

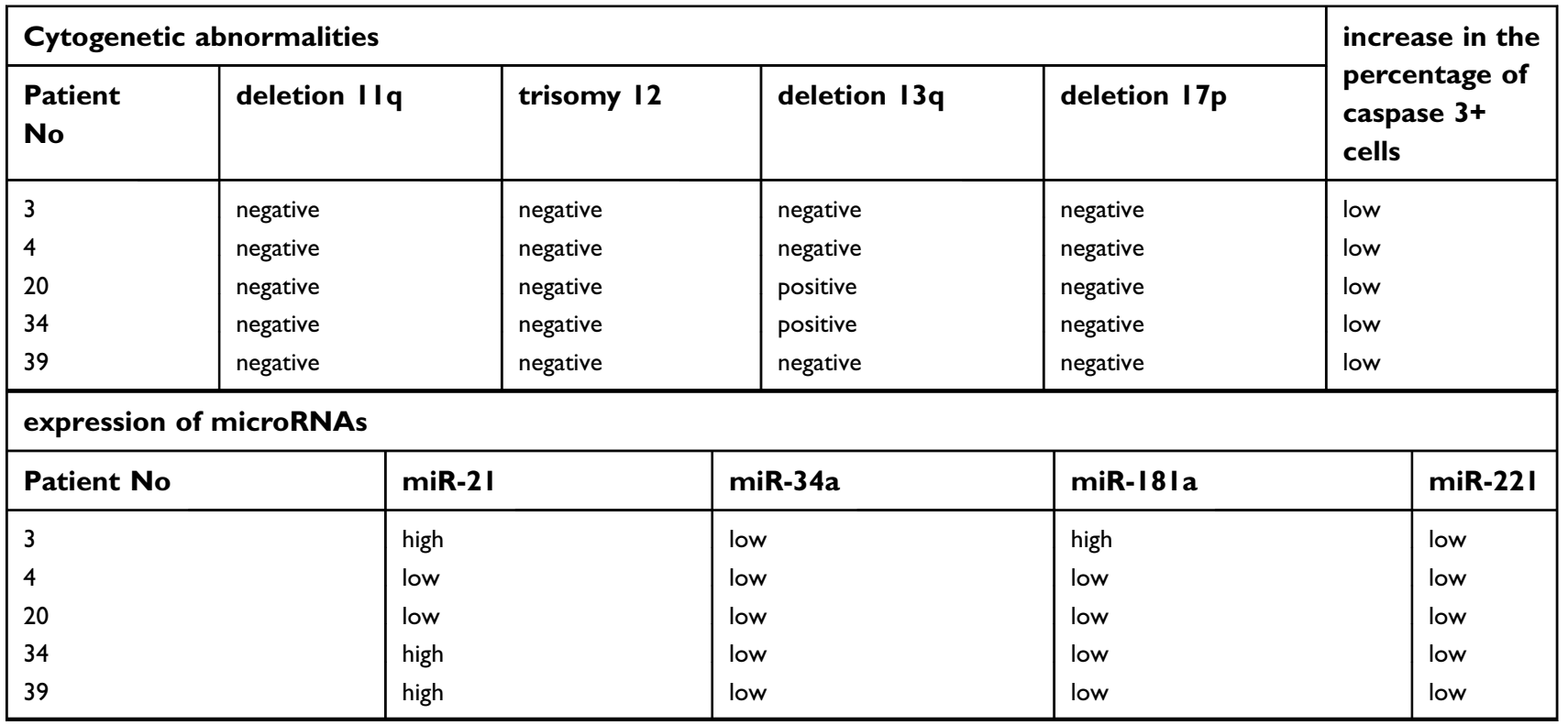




\section{Assessment of overall response rate in patients treated with fludarabine-based regimens with regards to microRNAs expression}

Fludarabine-based treatment was done in nine of 40 analyzed patients (seven patients received fludarabine in combination with cyclophosphamide; two patients received fludarabine in combination with cyclophosphamide and rituximab in full dose). Seven patients achieved response to therapy (complete remission or partial remission), while two of nine did not respond (none of them received fludarabine in combination with cyclophosphamide and rituximab). We compared the expression of all analyzed microRNAs in the group of responders versus nonresponders. The analyzed groups were small and the statistically significant differences were not achieved. The results are presented in Table 6. In the studied group there were no patients treated with cladribine-based chemotherapy, so the analysis of in vivo effects of cladribine was not performed.

\section{Discussion}

Numerous markers of prognostic relevance have been identified for CLL, like laboratory parameters reflecting the tumor burden or disease activity and markers related to the biology of leukemia. ${ }^{20,21}$ Some of them are used to predict chemotherapy outcome. Deletion of the short arm of chromosome 17 (del17p) is found in some patients resistant to chemotherapies like purine analogues or alkylating agents. These deletions include in the majority of cases a band $17 \mathrm{p} 13$, where TP53 gene is located. TP53 is considered as the prominent tumor suppressor gene. ${ }^{22,23}$ In patients without del17p, TP53 mutations are rarely detected, but have a similarly unfavorable effect on chemotherapy response and patients survival. ${ }^{21}$ The other factors involved in therapy resistance are still being investigated.

In the presented study we tried to analyze the possible role of chosen microRNAs expression miR-21, miR-34a, miR-181a and miR-221 as markers predicting the outcome of chemotherapy based on PNA fludarabine and cladribine in in vitro and in vivo conditions. Firstly, an increase in the percentage of apoptotic CD19+/CD5+/Cas3+ cells in PNAadded cultures had been analyzed in the group of patients with high versus low microRNA expression. We detected significantly higher fludarabine-induced apoptosis rate in patients with high miR-34a expression in comparison to low expression ones, which may indicate the possible role

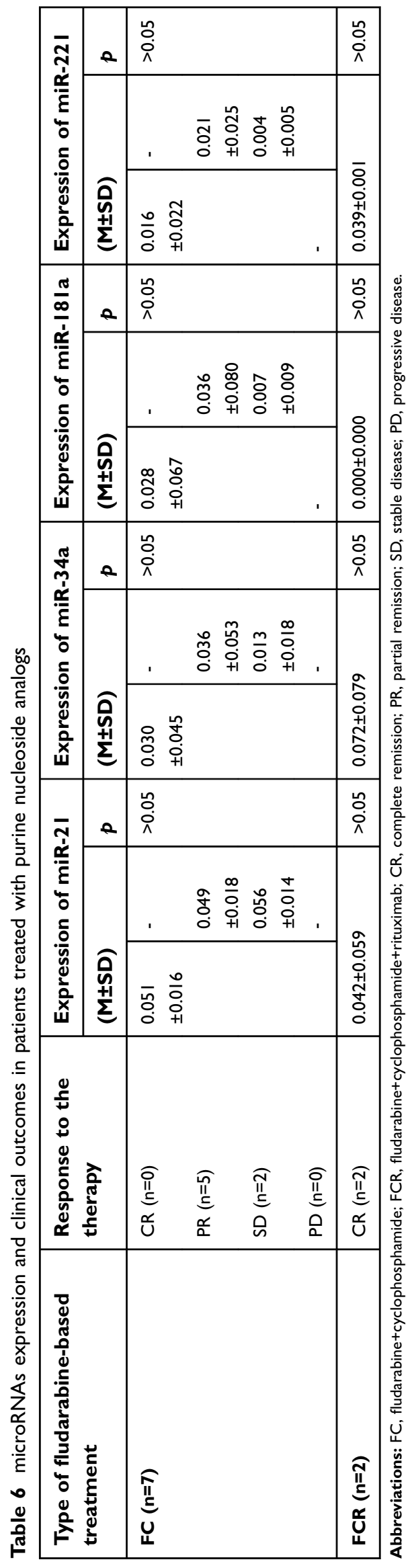


of this microRNA as a predictor of fludarabine-based therapy outcome. In a further step in our research the analysis of the microRNA influence on fludarabine-induced apoptosis in different risk groups was performed. We detected a significant difference in apoptosis rates in low versus high miR-34a expression groups in standard cytogenetic patients. These results may prove an important role of miR-34a expression as a predictor of apoptosis even in case when other risk factors like cytogenetic abnormalities are absent. Additionally, the detailed case analysis revealed in five patients of the standard cytogenetic risk group the low rate of apoptosis. In these patients unfavorable profile of microRNAs was detected as well.

The role of different microRNAs as predictors of fludarabine-based therapy was reported previously. Zenz et $\mathrm{al}^{24}$ proved the decreased apoptosis rate of leukemic cells in CLL patients of unfavorable cytogenetic profile and low miR-34a expression, which may be connected with the fact that miR-34a expression is controlled by

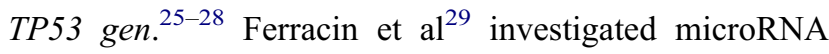
expression in fludarabine-treated CLL patients. The authors revealed fludarabine-resistance in abnormal p53 protein and overexpression of miR-21, miR-148a and miR-222. Inhibition of miR-21 and miR-222 resulted in increase of apoptosis rate in MEG-01 cell line with defect of p53 protein. $^{29}$

It was earlier reported that resistance to apoptosis in in vitro conditions may reflect such a resistance in vivo, thus abnormalities in microRNAs expression influencing the rate of in vitro apoptosis may be predictors of therapy outcome in vivo. ${ }^{30-32}$ In the presented study such an analysis with regards to results of fludarabine-based chemotherapy was performed, but the number of subjects enrolled was too small to obtain statistically significant results. However visible differences had been detected the expression of miR-34a. miR-221 and miR-181a were lower in the non-responders group in comparison to responders, while miR-21 expression was higher in nonresponders than in the responder group.

As far as cladribine was concerned we proved no differences in percentage of apoptotic cells in the group of patients with high expression of analyzed microRNAs in comparison to the group of low microRNAs expression. However, in the group of standard cytogenetic risk the percentage of cladribine-induced apoptotic cells was higher in high expression of miR-34a cases than in low miR-34a expression. The detailed case analysis revealed the absence of unfavorable cytogenetic risk factors and unfavorable profile of analyzed microRNA expression in six patients. Similarly to fludarabine the relation between response to cladribine in vitro reflects the therapy outcome in vivo. ${ }^{33,34}$ Based on this result we might conclude that, in particular, miR-34a expression may be a predictor of response to cladribine even with the absence of other predictors like cytogenetic ones.

\section{Conclusions}

To summarize, an assessment of microRNAs expression may be a useful indicator of sensitivity to PNA both in vivo and in vitro. The low expression of miR-34a seems to be involved, among other factors, in fludarabineinduced apoptosis inhibition in cell culture condition. Such relation between apoptosis and miR-34a expression is observed mainly in the absence of unforeseeable risk cytogenetic abnormalities in leukemic cells. Similarly, an inhibition of proapoptotic effect of cladribine in in vitro cultures seems to be connected with miR-34a expression and it is most detectable in the absence of unforseeable risk cytogenetic changes. Thus further studies are required to describe precisely the role of microRNAs expression in predicting therapy outcome and their usefulness in clinical practice.

\section{Abbreviation list}

CLL, chronic lymphocytic leukemia; TTP, time to progression; PFS, progression free survival; OS, overall survival time; miR, microRNA; MoAb, monoclonal antibody; IgVH, immunoglobulin heavy chain genes; PBMC, peripheral blood mononuclear cells; qRT-PCR, quantitative reverse transcriptase real-time PCR; cDNA, complementary DNA; Ct, cycle threshold; MACS, magnetic activated cell sorting; FISH, fluorescence in situ hybridization.

\section{Ethics approval and consent to participate}

This study was approved by the Ethics Committee of the Medical University of Lublin (KE No. 0254/260/2015). All patients were asked to sign the informed consents. The study was conducted in accordance with the ethical standards of the Declaration of Helsinki.

\section{Acknowledgments}

This study was funded by a research grant from the Medical University of Lublin [DS176]. 


\section{Disclosure}

The authors report no conflicts of interest in this work.

\section{References}

1. Tausch E, Mertens D, Stilgenbauer S. Advances in treating chronic lymphocytic leukemia. F1000 Prime Rep. 2014;6:65. doi:10.12703/P

2. Byrd JC, Jones JJ, Woyach JA, Johnson AJ, Flynn JM. Entering the era of targeted for chronic lymphocytic leukemia: impact on the practicing clinician. J Clin Oncol. 2014;32:3039-3047. doi:10.1200/ JCO.2014.55.8262

3. Cuneo A, Cavazzini F, Ciccone M, et al. Modern treatment in chronic lymphocytic leukemia: impact on survival and efficacy in high-risk subgroups. Cancer Med. 2014;3:555-564. doi:10.1002/cam4.226

4. Fischer K, Hallek M. Optimizing frontline therapy of CLL based on clinical and biological factors. Hematology Am Soc Hematol Educ Program. 2017;8:338-345.

5. Furman RR. Prognostic markers and stratification of chronic lymphocytic leukemia. Hematology Am Soc Hematol Educ Program. 2010;2010:77-81.

6. Zenz T, Fröhling S, Mertens D, Döhner H, Stilgenbauer S. Moving from prognostic to predictive factors in chronic lymphocytic leukemia (CLL). Best Pract Res Clin Haematol. 2010;23:71-84.

7. Kipps TJ, Stevenson FK, Wu CJ, et al. Chronic lymphocytic leukemia. Nat Rev Dis Primers. 2017;3:17008. doi:10.1038/nrdp.2017.8

8. Hallek M. Chronic lymphocytic leukemia: 2015 Update on diagnosis, risk stratification, and treatment. Am J Hematol. 2015;90:446-460.

9. Cramer P, Hallek M, Eichhorst B. State-of-the-art treatment and novel agents in chronic lymphocytic leukemia. Oncol Res Treat. 2016;39:25-32.

10. Yeh $\mathrm{CH}$, Moles R, Nicot C. Clinical significance of microRNAs in chronic and acute human leukemia. Mol Cancer. 2016;15:37. doi:10.1186/s12943-016-0518-2

11. Fischer SE. RNA interference and microRNA-mediated silencing. Curr Protoc Mol Biol. 2015;112:1-5. doi:10.1002/0471142727. $\mathrm{mb} 2601 \mathrm{~s} 112$

12. Almeida MI, Reis RM, Calin GA. MicroRNA history: discovery, recent applications, and next frontiers. Mutat Res. 2011;717:1-8. doi:10.1016/j.mrfmmm.2011.03.009

13. MacFarlane LM, Murphy PR. MicroRNA: biogenesis, function and role in cancer. Curr Genomics. 2010;11:537-561. doi:10.2174/ 138920210793175895

14. Cimmino A, Calin GA, Fabbri M, et al. miR-15 and miR-16 induce apoptosis by targeting BCL2. Proc. Natl Acad Sci USA. 2005;102:13944-13949. doi:10.1073/pnas.0506654102

15. Szymczyk A, Chocholska S, Macheta A, Szczepanek D, Hus M, Podhorecka M. Assessment of micro RNAs expression in leukemic cells as prognostic markers in chronic lymphocytic leukemia: micro RNAs can predict survival in a course of the disease. Oncotarget. 2018;9:19136-19146. doi:10.18632/oncotarget.24927

16. Chomczynski P, Sacchi N. Single-step method of RNA isolation by acid guanidinium thiocyanate-phenol-chloroform extraction. Anal Biochem. 1987;162:156-159. doi:10.1006/abio.1987.9999

17. Chen C, Ridzon DA, Broomer AJ, et al. Real-time quantification of microRNAs by stem-loop RT-PCR. Nucleic Acids Res. 2005;33:e179. doi:10.1093/nar/gni178

18. Hallek M, Cheson BD, Catovsky D, et al. Guidelines for the diagnosis and treatment of chronic lymphocytic leukemia: a report from the International Workshop on Chronic Lymphocytic Leukemia updating the National Cancer Institute-Working Group 1996 guidelines. Blood. 2008;111:5446-5456. doi:10.1182/blood-2007-06-093906
19. Cheson BD, Bennett JM, Grever M, et al. National Cancer Institute-sponsored Working Group guidelines for chronic lymphocytic leukemia: revised guidelines for diagnosis and treatment. Blood. 1996;87:4990-4997.

20. Nabhan C, Gartenhaus RB, Tallman MS. Purine nucleoside analogues and combination therapies in B-cell chronic lymphocytic leukemia: dawn of a new era. Leuk Res. 2004;28:429-442. doi:10.1016/j. leukres.2003.08.017

21. Seiffert M, Dietrich S, Jethwa A, Glimm H, Lichter P, Zenz T. Exploiting biological diversity and genomic aberrations in chronic lymphocytic leukemia. Leuk Lymphoma. 2012;53:1023-1031. doi:10.3109/10428194.2011.631638

22. Hallek M, Fischer K, Fingerle-Rowson G, et al. Addition of rituximab to fludarabine and cyclophosphamide in patients with chronic lymphocytic leukaemia: A randomised, open-label, phase 3 trial. Lancet. 2010;376:1164-1174. doi:10.1016/S0140-6736(10)61381-5

23. Kobylinska A, Bednarek J, Blonski JZ, et al. In vitro sensitivity of B-cell chronic lymphocytic leukemia to cladribine and its combinations with mafosfamide and/or mitoxantrone. Oncol Rep. 2006;16:1389-1395.

24. Zenz T, Häbe S, Denzel T, et al. Detailed analysis of p53 pathway defects in fludarabine-refractory chronic lymphocytic leukemia (CLL): dissecting the contribution of $17 \mathrm{p}$ deletion, TP53 mutation, p53-p21 dysfunction, and miR34a in a prospective clinical trial. Blood. 2009;114:2589-2597. doi:10.1182/blood-2009-05-224071

25. Bommer GT, Gerin I, Feng Y, et al. p53-mediated activation of miRNA34 candidate tumor-suppressor genes. Curr Biol. 2007;17:1298-1307. doi:10.1016/j.cub.2007.06.068

26. Chang TC, Wentzel EA, Kent OA, et al. Transactivation of miR-34a by p53 broadly influences gene expression and promotes apoptosis. Mol Cell. 2007;26:745-752. doi:10.1016/j.molcel.2007.05.010

27. He L, He X, Lim LP, et al. A microRNA component of the p53 tumour suppressor network. Nature. 2007;447:1130-1134. doi:10.1038/nature05939

28. Tarasov V, Jung P, Verdoodt B, et al. Differential regulation of microRNAs by $\mathrm{p} 53$ revealed by massively parallel sequencing: miR-34a is a p53 target that induces apoptosis and G1-arrest. Cell Cycle. 2007;6:1586-1593. doi:10.4161/cc.6.13.4436

29. Ferracin M, Zagatti B, Rizzotto L, et al. MicroRNAs involvement in fludarabine refractory chronic lymphocytic leukemia. Mol Cancer. 2010;9:123. doi:10.1186/1476-4598-9-254

30. Castejón R, Yebra M, Citores M-J, Villarreal M, García-Marco JA, Vargas JA. Drug induction apoptosis assay as predictive value of chemotherapy response in patients with B-cell chronic lymphocytic leukemia. Leuk Lymphoma. 2009;50:593-603. doi:10.1080/ 10428190902780669

31. Sieklucka M, Pozarowski P, Bojarska-Junak A, Hus I, Dmoszynska A, Rolinski J. Apoptosis in B-CLL: the relationship between higher ex vivo spontaneous apoptosis before treatment in III-IV Rai stage patients and poor outcome. Oncol Rep. 2008;19:1611-1620.

32. Podhorecka M, Klimek P, Chocholska S, et al. The rate of in vitro fludarabine-induced peripheral blood and bone marrow cell apoptosis may predict the chemotherapy outcome in patients with chronic lymphocytic leukemia. Eur J Clin Pharmacol. 2015;71:1121-1127. doi:10.1007/s00228-015-1893-0

33. Bromidge TJ, Turner DL, Howe DJ, Johnson SA, Rule SA. In vitro chemosensitivity of chronic lymphocytic leukaemia to purine analogues - correlation with clinical course. Leukemia. 1998;12:1230-1235.

34. Żołnierczyk JD, Borowiak A, Błoński JZ, et al. In vivo and ex vivo responses of CLL cells to purine analogs combined with alkylating agent. Pharmacol Rep. 2013;65:460-475. 


\section{Publish your work in this journal}

Cancer Management and Research is an international, peer-reviewed open access journal focusing on cancer research and the optimal use of preventative and integrated treatment interventions to achieve improved outcomes, enhanced survival and quality of life for the cancer patient.

The manuscript management system is completely online and includes a very quick and fair peer-review system, which is all easy to use. Visit http://www.dovepress.com/testimonials.php to read real quotes from published authors.

Submit your manuscript here: https://www.dovepress.com/cancer-management-and-research-journa 